\title{
Soft tissue profile analysis using loi's method for dentoalveolar bimaxillary protrusion cases before and after treatment with extractions of four first premolars
}

\author{
Yuliana Ziliwu, Tono S. Hambali, Jono Salim, Endah Mardiati \\ Department of Orthodontics Faculty of Dentistry Universitas Padjadjaran
}

\section{ABSTRACT}

The purpose of this study is to measure the soft tissue profile changes before and after treatment of dento-alveolar bimaxillary protrusion cases which had orthodontic treatment including extraction of upper and lower first premolars. loi's soft tissue analysis used in this study and cephalometic analysis on 14 patients wich fulfilled sample criteria was performed. Four angular and two linear measurement was done manually utilizing protractor. Statistical analysis was paired t-test. Result showed significant changes in soft tissue after the treatment.

Key words: Soft tissue profile, loi's method, dento-alveolar bimaxillary protrusion, extractions of four first premolars

\section{INTRODUCTION}

The main objective of orthodontic treatment is to obtain optimal occlusal function and to correct facial aesthetic. ${ }^{1}$ Clinical research and observation show that treatment result will be stable if there is balance between teeth and surrounding muscles. Soft tissue plays an important role in facial aesthetic, speech function and other physiological functions. The success of orthodontic care closely relates to facial soft tissue change. ${ }^{2}$

Patients with dentoalveolar bimaxillary protrusion have convex face profiles due to protrusive position of incisive teeth in the maxilla and in the lower jaw. ${ }^{3}$ The objective of bimaxillary protrusion treatment is to decrease soft tissue convexity by retracting upper and lower incisors. ${ }^{4}$ Kusnoto et al. ${ }^{5}$ states another objective that is to lessen lower face and lip convexity. Dentoalveolar bimaxillary protrusion treatment is commonly conducted by extracting four first premolar teeth followed by canine retraction and the four incisive. Because of this incisors, soft profile changing takes place..$^{3-5}$ The success of dentoalveolar bimaxillary treatment which is done by extraction the four first premolar teeth followed by canine and the four incisor retraction have been reported.

Lew et al. ${ }^{6}$ studied dentoalveolar bimaxillary protrusion profile change which was treated by extracting four first premolar teeth. In 32 Asian adults, at the end of treatment correction takes place in which teeth protrusion and teeth in the maxilla and lower jaw decreased, upper and lower lips length extends, upper lip decreased and lower lip protrusion decreased and nasobial fold increased. 
Kusnoto et al. ${ }^{5}$ studied the effect of anterior teeth retraction toward upper and lower lips position in dentoalveolar bimaxillary protrusion which was treated by extraction four first premolar teeth in $\mathbf{4 0}$ Indonesian patients aged 15 years old or more. In the end of treatment, upper and lower lips are retrusive, nasolabial and labiomental angle increased.

Bills et al. ${ }^{4}$ studied orthodontic treatment effects toward soft tissue in dentoalveolar bimaxillary protrusion treated by extracting four first premolar teeth, in 48 people, male and female aged 15-18 years old, linear and angular cephalometric $\mathrm{x}$-ray measurement before and after treatment showed that at the end of treatment, teeth protrusion decreased, upper and lower lips convexity and face soft tissue convexity decreased.

In order to achieve treatment objective, it is important for the clinical practitioners to determine correct diagnosis and treatment plan. Of the basic components of determining orthodontic diagnosis and treatment plan is analyzing soft tissue. $^{7}$ There are various types of soft tissue profile analysis. One of which is lower part of face analysis; that is by determining nasal, labial and chin correlation..$^{8,9}$ This analysis is very important to determine harmonic face aesthetics.

Generally an orthodontic treatment plan which only focuses on dento-skeletal hard tissue without paying attention to soft tissue often makes it hard to predict soft tissue state in the end of treatment. ${ }^{10}$ But, soft tissue analysis is not done often because there is an opinion stating that by doing dento-skeletal correction, soft tissue will be affected automaticcally. ${ }^{2}$ According to Kasai ${ }^{11}$ soft tissue does not always follow dento-skeletal alterations because soft tissue covering teeth and skeleton varies on its thickness and tension.

There are several methods to measure soft tissue namely Ricketts method, Steiner method, Merrifield method, Burstone method, Sushner method, Holdaway method ${ }^{2}$, loi et al method. ${ }^{7}$ All those methods use lip position as parameter.

loi et al. ${ }^{7}$ uses lateral cephalometric x-ray to measure soft tissue profile in antero-posterior direction in angular and linier way. With this method, loi et al. studied antero-posterior soft tissue profile in 30 Japanese aged $22-26$ years old. One of the soft tissue analysis strengths using loi et al. ${ }^{7}$ method is that it is easy to do.

According toBillsetal. ${ }^{4}$ bimaxillaryprotrusion is a state of maxillary and lower jaw incisive teeth protrusion with significant lips convexity. Because the negative perception toward protrusive teeth and lips, many patients with this malocclusion want orthodontic treatment to reduce the face, lips and teeth convexity. Bimaxillary protrusion is often seen in Asia, Africa-America populations and Indonesian people face profile also tends towards bimaxillary protrusion. ${ }^{5}$

Bimaxillary protrusion can be divided into: ${ }^{8,12,13}$ (1) Bimaxillary prognathism. According to Graber ${ }^{14}$, bimaxillary prognathism has a convex face profile characteristic, mandible and maxillary relation toward skeleton basic bone is more forward than it should be, but with class I teeth relation. Moyers ${ }^{12}$ stated that skeletal bimaxillary protrusion or bimaxillary prognathism is caused by an abnormal mandible and maxillary development and the relation of both toward cranium is more forward. The long axis of incisive follows excessive maxillary and mandible basal bone growth. This condition is a skeletal disorder. (2) Dentoalveolar bimaxillary protrusion. According to Moyers ${ }^{12}$, dentoalvolar bimaxillary or bimaxillary dental protrusion is a condition where the alveolar bone and dental arch development towards maxillary and mandible basal bones are excessive. Maxillary and mandible basal bones have a normal relationship to cranium, but the dentoalveolar inclination is more forward and this condition is a dental disorder. Krutz et al. ${ }^{15}$ suggested that the disorder has a class I characteristics, protrusive teeth, protrusive lips, convex face and the incisive position is more labial against maxillary and mandible apical basis and skeletal profile. (3) Neuromuscular dentoalveolar bimaxillary protrusion. According to Rakosi el $\mathrm{al}^{8}$, in this maloclussion, a dentoalveolar disorder in neuromuscular system is found, where the lips are open because the lips and tongue muscle is disturbed, incisive inclination to labial happens because of hyperactive tongue muscles. The face appearance becomes unesthetic. This disorder is often affected by heredity and race. (4) Combined bimaxillary protrusion between bimaxillary prognathism and dentoalveolar bimaxillary protrusion. This malocclusion is very complex because it is a combination of bimaxillary prognathism and dento-alveolar bimaxillary 
protrusion. This type of disorder involves dental and skeletal aspects. ${ }^{12}$

loi et al. ${ }^{7}$ research is performed to understand the soft tissue profile in an anteroposterior direction on 30 Japanese face profiles, age range of 22-26 years old. Measurement in this study ${ }^{16,7}$ are: nose point angle, i.e. an angle that is constructed by nose tangent ( $\mathrm{N}^{\prime}-\mathrm{Pn}$ : softpronasal tissue nation) with $\mathrm{N}^{\prime}$-Pg' line (soft tissue soft-pogonion soft nation); columella angle, i.e. angle that is constructed by nose tangent $\left(\mathrm{N}^{\prime}\right.$ $\mathrm{Pn}$ : soft-pronasal tissue nation) with nasofacial tangent ( $\mathrm{N}$ '-Sn: soft-subnation tissue nation); nose end angle, i.e. angle that is constructed by nose tangent ( $\mathrm{N}^{\prime}-\mathrm{Pn}$ : soft pronasal tissue nation) with columella tangent ( $\mathrm{Sn}-\mathrm{Cm}$ : subnasal-columella); nasolabial angle $(\mathrm{Cm}-\mathrm{Sn}-\mathrm{Ls})$, i.e. angle that is constructed by $\mathrm{Cm}$ (columella), Sn (Subnasal) and Ls (Labialis superior); upper lips protrusion (Ls to Sn-Pg'), i.e. Ls (labialis superior) distance to Sn-Pg' (sub nasal-soft tissue pogonion); lower lips protrusion (Li to Sn-Pg'), i.e. Li (labialis inferior) distance to Sn-Pg' (subnasal-soft tissue pogonion); lower lips sulcus angle ( $\mathrm{Li}^{\mathrm{B}} \mathrm{B}$ '-Pg'), i.e. angle that is constructed by Li (labialis inferior), B' (lower lips sulcus); Pg' (soft tissue pogonion); convexity angle, i.e. angle that is constructed by G' (soft tissue glabela), Sn (Subnasal) and Pg' (soft tissue progonion); $Z$ angle, i.e. angle that is constructed by line connecting Pg' (soft tissue pogonion) to $\mathrm{Li}$ (labialis inferior) intersecting with Frankfort Horizontal Plane (Fig. 2)

\section{MATERIALS AND METHODS}

The study objects consist of 28 lateral cephalometric $\mathrm{x}$-ray photos before and after treatment from 14 patients with dento-alveolar bimaxillary protrusion malocclusion who have finished their treatment that include four premolar extractions and Standard Edgewise fixed orthodontic appliance at Orthodontic Specialist Programme Clinic, Faculty of Dentistry Universitas Padjadjaran between 1997-2006.

The instruments used in this study include: illuminator lamp, Ortho Organizers Protactor, Staedler $4 \mathrm{H}$ pencil, Staedler rubber eraser, and cellotape.

Inclusion sample criteria: Dento-alvolar bimaxillary protrusion malocclusion patients; More than 16 years of age, male and female; Lateral cephalometric $\mathrm{x}$-rays before and after treatment are complete and in good condition; Treatment included four premolar extractions; and Standard Edgewise Fixed orthodontic appliance.

Dento-alveolar bimaxillary protrution is a condition where the dental arch and the alveolar bone grow extensively compared to the upper basal bone and lower jaw with a skeletal class I relation and convex facial profile. SNA $82^{\circ} \pm 2$, SNB $80^{\circ} \pm 2$, ANB $2-3^{\circ}$, upper I angle towards $\mathrm{N}$-A line is more than $32^{\circ}$, upper I distance to $\mathrm{N}-\mathrm{A}$ line is more than $6 \mathrm{~mm}$, lower I angle towards N-B more than $32^{\circ}$, lower I distance towards N-B more than $6 \mathrm{~mm}$.

Frankfort Horizontal Plane is a plane made through the superior part of porion point and inferior part of orbital point. ${ }^{5}$ The soft tissue esthetic plane is a plane made of $\mathrm{N}^{\prime}$ point (soft tissue nation) with Pg' point (soft tissue pogonion).

\section{Reference point}

Soft tissue profile anatomical points: ${ }^{5,7,17,18}$ (1) Point G' (soft tissue glabella) is the most prominent point of the forehead soft tissue at the midsagittal plane. Point $G^{\prime}$ is determined by projecting point $G$ in parallel with Frankfort Horizontal Plane to forehead soft tissue; (2) N' Point (soft tissue nasion) is the most concave point in soft tissue covering frontonasal suture area. N' point is determined by projecting point $\mathrm{N}$ parallel to Frankfort Horizontal Plane to nasal soft tissue; (3) Point $\mathrm{Cm}$ (columella) is the most antero-inferior point in nasal columella. Point $\mathrm{Cm}$ is determined by making collumella tangent from point $\mathrm{Sn}$ (subnasal) and then determine the most anteroinferior point; (4) Point Pn (pronasal) is the point on the tip of the nose; (5) Point Sn (Subnasal) is the meeting point between columella and upper lip in the midsagittal plane (6) Point Ls (Labialis Superior) is the most anterior in the upper lip; (7) Point Li (Labialis Inferior) is the most anterior in the lower lip; (8) Point B' (supramentale/lower lip sulcus) is the most concave point between $\mathrm{Li}$ (labialis inferior) and ( $\left.\mathrm{Pg}^{\prime}\right)$ pogonion of the soft tissues; (9) Point Pg' (Pogonion of the soft tissues) is the most anterior point on the chin soft tissue. The method to determine point Pg' is by projecting point $\mathrm{Pg}$ in parallel with Frankfort 
Horizontal Plane to the chin soft tissue; (10) Point Me' (Menton of the soft tissues) is the most inferior in the chin soft tissues. The method to determine point Me' is to project point Me in parallel with Frankfort Horizontal Plane to the chin soft tissue.

This study is an analytical descriptive study. The study data is analyzed using test-t for paired data. The significance is determined base on $p$ value $<0.05$.

\section{RESULTS}

Data from the soft tissue profile analysis results on 14 patients before and after treatment can be referred in Table 1.

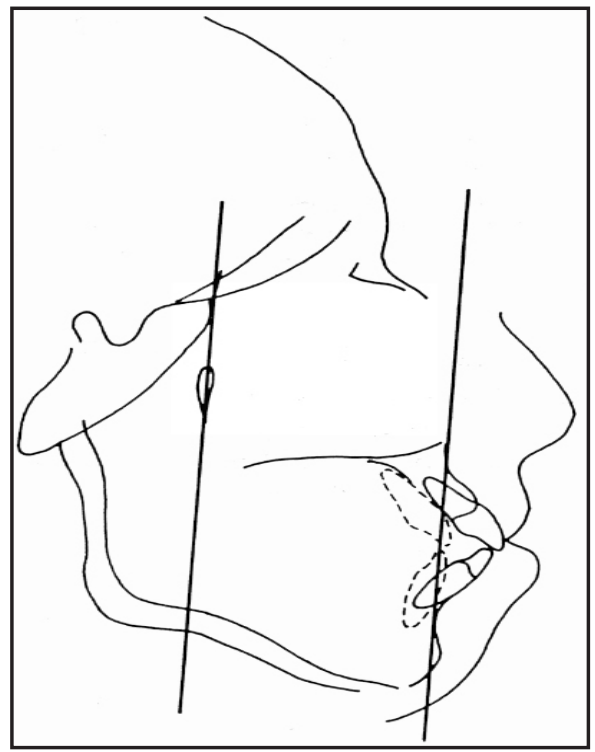

Figure 1. Bimaxillary prognathism. ${ }^{12}$

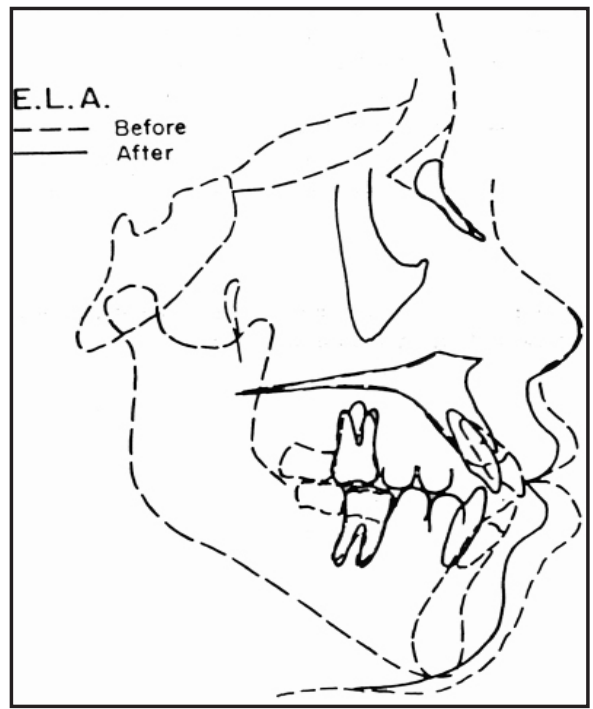

Figure 2. Dental dentoalveolar bimaxillary protrusion. ${ }^{12}$

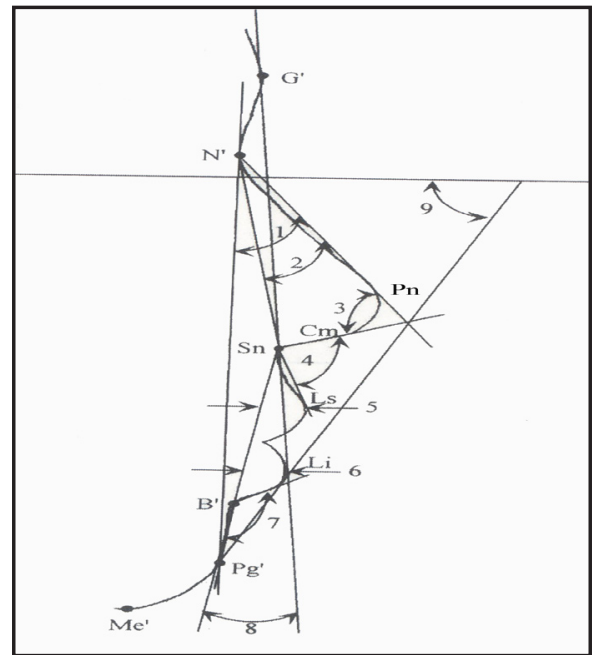

Figure 3. Soft tissue profile cephalometry analysis reference line and point according to loi. ${ }^{7} 1$. Nose pointy angle (B'-N' with N'-Pn); 2. Columella angle (Sn-N' with $\left.\mathrm{N}^{\prime}-\mathrm{Pn}\right) ; 3$. Nose end angle ( $\mathrm{Sn}-\mathrm{Cm}$ with $\left.\mathrm{Pn}-\mathrm{N}^{\prime}\right)$; 4. Nasolabial angle $(\mathrm{Cm}-\mathrm{Sn}-\mathrm{Ls}) ; 5$. Upper lips protrusion (Ls toward SnPg'); 6. Lower lips protrusion (Li toward Sn-Pg'); 7. Lower lips sulcus angle (Li-B'-Pg'); 8. Convexity angle (G'-Sn-Pg');

9. Z angle (Pg'-Li intersecting with Horizontal Frankfort Plane).

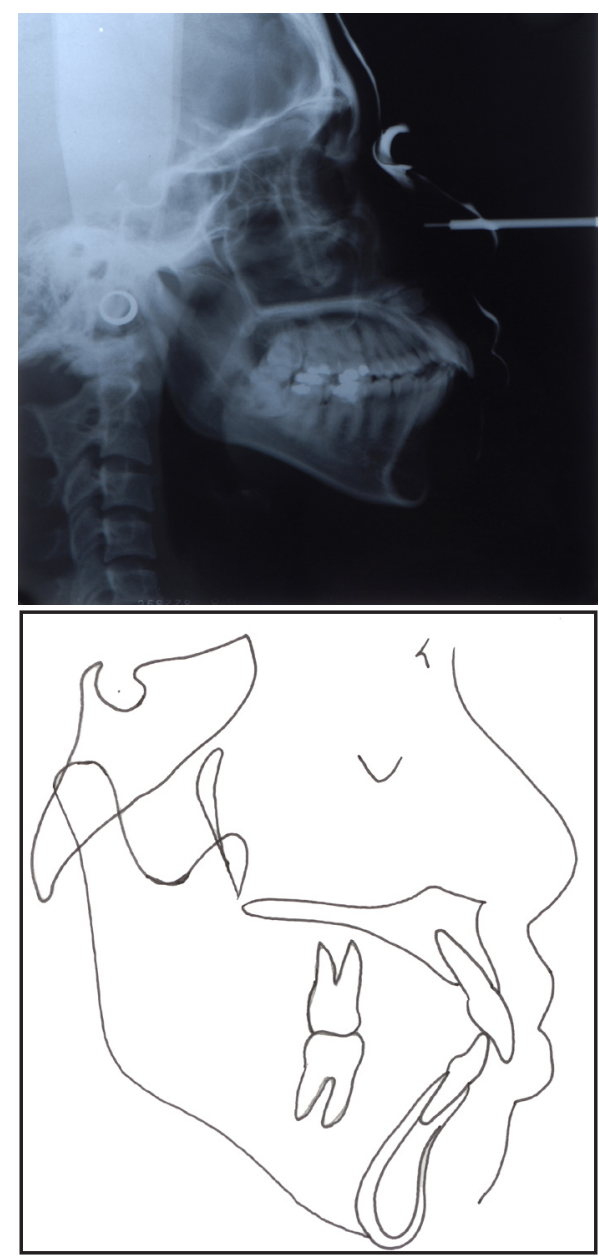

Figure 4. Study materials. Upper: Cephalometric X-rays; Lower: Acetate paper. 
Soft tissue profile measurement using loi method

In Table 1 it is apparent that there is a difference in soft tissue after treatment with four first premolar extraction. The nasolabial angle increases averagely $4.21^{\circ}\left(S D \pm 3.53^{\circ}\right)$, lower lip sulcus angle increases averagely $6.43^{\circ}$ (SD \pm $\left.7.78^{\circ}\right)$, convexity angle decreases averagely $1.93^{\circ}$ $\left(\mathrm{SD} \pm 1.21^{\circ}\right)$, angle $\mathrm{Z}$ increases averagely $4.86^{\circ}$ (SD $\left.\pm 2.84^{\circ}\right)$, upper lip protrusion decreases averagely $1.79 \mathrm{~mm}(\mathrm{SD} \pm 1.19 \mathrm{~mm})$ and lower lip protrusion decreases averagely $2.5 \mathrm{~mm}(\mathrm{SD} \pm 1.61 \mathrm{~mm})$.

\section{DISCUSSION}

Soft tissue profile analysis using loi in the dentoalveolar bimaxillary malocclusion can be used to see the soft tissue profile changes before and after treatment.

\section{Soft tissue profile analysis on nasolabial angle}

Based on this study results at the end of bimaxillary protrusion treatment with four first premolar extraction it is revealed that the nasolabial angle (SNL) increased. According to Fitzgerald et al. ${ }^{19}$ the nasolabial angle is an important angle to be attended during orthodontic treatment. The effects of upper incisive retraction influence on the upper lips are seen on the nasolabial angle measurement that increased at the end of the treatment. In the study of Fitzgerald et al. ${ }^{19}$ among white samples it is revealed that the nasolabial average angle is $114^{\circ}$ $\pm 10^{\circ}$, while among white samples it is revealed that the nasolabial average angle is $114^{\circ} \pm 10^{\circ}$, while Viazis ${ }^{20}$ stated that the average nasolabial angle $100^{\circ}\left(S D \pm 10^{\circ}\right)$. This study results are similar to the results of study from Lew et al.5,6,10,21 stating that dentoalveolar bimaxillary treatment with four first premolar extraction and incisive retraction make the nasolabial angle increase.

The nasolabial average angle value in this research before treatment is $99.93^{\circ}$ and $104.14^{\circ}$ after treatment. The results of the study from Kusnoto et al. $^{5}$ before treatment is $97.0^{\circ}$ (SD \pm $\left.13.29^{\circ}\right)$ and after treatment $104.8^{\circ}\left(S D \pm 14.08^{\circ}\right)$. The nasolabial average value in this study is similar to the average value of Caucasoid race nasolabial angle, i.e. 90-120 21 , although the samples used in this study is the Deutro-Malay race. The nasolabial angle average value in this research approaches the results of loi et al. ${ }^{7}$ research in Japanese, i.e. $93.8^{\circ}$ in male and $99.8^{\circ}$ in female.

\section{Soft tissue profile analysis on lower lip sulcus angle}

Based on the study result at the end of bimaxillary protrusion treatment with four first premolar extraction, it is shown that there is a significant increase in lower lip sulcus angle (SSBB). Kusnoto et al. ${ }^{5}$ stated that the lower lip sulcus increases at the end of treatment with four first premolar extractions.

Farrow et al. ${ }^{3}$, Bergman ${ }^{10}$, Lew et al. ${ }^{6}$ also stated that upper anterior tooth retraction will retract the lower lip. According to Kusnoto ${ }^{5}$ this is due to the fact that lips are supported by hard tissues that experience changes due to orthodontic treatment. The lower incisive retraction makes the lower lip moves backward. Kusnoto et al. ${ }^{5}$ in his study reports that the increased lower lip sulcus angle caused by four first premolar extraction before treatment $129^{\circ}$ is $\left(S D \pm 17.37^{\circ}\right)$, and $136.4^{\circ}$ after treatment $\left(S D \pm 17.52^{\circ}\right)$. Based on this result,

Table 1. Average results form nasolabial angle, lower lip sulcus angle, convexity angle, $\mathrm{Z}$ angle, upper lip protrusion and lower lip protrusion.

\begin{tabular}{ccccccc}
\hline Variable & Before & SD & After & SD & Difference & SD \\
\hline SNI & 99.93 & \pm 9.41 & 104.14 & \pm 8.07 & 4.21 & \pm 3.53 \\
SSBB & 124.43 & \pm 18.61 & 130.86 & \pm 17.56 & 6.43 & \pm 7.78 \\
SK & 13.79 & \pm 5.98 & 11.86 & \pm 6.14 & 1.93 & \pm 1.21 \\
SZ & 62.64 & \pm 8.40 & 67.57 & \pm 8.72 & 4.86 & \pm 2.84 \\
PBA $(\mathrm{mm})$ & 9.00 & \pm 2.04 & 7.21 & \pm 2.01 & 1.79 & \pm 1.19 \\
PBB $(\mathrm{mm})$ & 8.78 & \pm 2.75 & 6.28 & \pm 2.55 & 2.50 & \pm 1.61 \\
\hline
\end{tabular}

Note: SD: Standard Deviation; SNL: Nasolabial Angle; SZ: Z Angle; SSBB: Lower Lip Sulcus Angle; PBA: Upper Lip Protrusion; SK: Convexity Angle; PBB: Lower Lip Protrusion. 
the lower lip sulcus angle increases $6.43^{\circ}$ (before $124.43^{\circ}$, after $130.86^{\circ}$ ) meanwhile in the study of Kusnoto et al. ${ }^{5}$ it increases $7.25^{\circ}$. The average value of low lip sulcus angle for Caucasoid race is $122^{\circ}$ with a range of $110^{\circ}-134^{0},{ }^{10}$ the average low lip sulcus angle value in this research before treatment $\left(124.43^{\circ}\right)$ and after treatment $\left(130.86^{\circ}\right)$ is still in the average range of Caucasoid race although it is over the average value. This may happen due to the different race, treatment technique and sample size. The lower lip sulcus angle value in this research approaches the values in loi et al. ${ }^{7}$ study value among Japanese with the lower lip sulcus angle is $129.6^{\circ}$ in male and $140.5^{\circ}$ in female.

\section{Soft tissue profile analysis on convexity angle}

The result of this study on soft tissue profile towards convexity angle show a significant reduction at the end of bimaxillary protrusion with four first premolar extraction. This result is similar to the result from a study conducted by Bills et al. ${ }^{4}$ which shows a reduction of convexity angle or soft tissue convexity at the end of a treatment with four first premolar extraction. Bills et al. ${ }^{4}$ stated that by extracting four first premolars and retracting incisives the lips convexity and soft tissues will be reduced that, in turn, will reduce the convexity of the face. The reduction of the convexity angle in this research is due to the upper lip retraction causing changes in $\mathrm{Sn}$ point position of the soft tissue that the point G'-Sn-Pg' projection will be reduced. The convexity angle in this research before treatment is $13.79^{\circ}$ and $11,86^{\circ}$ after treatment constituting the change to $1.93^{\circ}$. This convexity angle value is approaching the results of loi et al. ${ }^{7}$ study among Japanese, i.e. $11.5^{\circ}$ in male and $13.2^{\circ}$ in female.

\section{Soft tissue profile analysis on $\mathrm{Z}$ angle}

The result from $Z$ angle soft tissue profile shows a significant increase at the end of bimaxillary protrusion treatment with four first premolar extraction with a value of $67.57^{\circ}$ (SD $\left.\pm 2.55^{\circ}\right)$ before treatment and $2.50^{\circ}\left(\mathrm{SD} \pm 1.61^{\circ}\right)$ after treatment. This result is similar to the results of James ${ }^{22}$ that stated that the more backward the lips, the bigger the $\mathrm{Z}$ angle. The $\mathrm{Z}$ angle is bigger due to the lower lip position projection (Li: labialis inferior) backward movement towards soft tissue pogonion point ( $\left(\mathrm{Pg}^{\prime}\right)$ which position does not change causing the $\mathrm{Z}$ angle made of $\mathrm{Pg}$ '- $\mathrm{Li}$ and intersecting with Frankfort Horizontal Plane bigger.

The value of $Z$ angle in this study is $62.64^{\circ}$ before treatment and $67.57^{\circ}$ after treatment with a change of $4.86^{\circ}$. The average value of $Z$ angle in Caucasoid race according to Merrifield is $72-83^{\circ}$. This $\mathrm{Z}$ angle value is almost similar to $\mathrm{Ioi}^{7}$ study results in male $\left(69.0^{\circ}\right)$ and female $\left(66.6^{\circ}\right)$.

\section{Soft tissue profile analysis on upper lip protrusion}

The results of soft tissue profile study show that the upper lip protrusion is decreased significantly in bimaxillary protrusion treatment with four first premolar extraction. The linier measurement of the upper lip protrusion in this study before treatment $(9.00 \mathrm{~mm})$ and after treatment $(7.21 \mathrm{~mm})$ shows a change of 1.79 compared to the results of Kusnoto et al. ${ }^{5}$ in dentoalveolar bimaxillary protrusion treated by four first premolar extraction among Indonesian. The upper lip protrusion before treatment $(89.5$ $\mathrm{mm})$ and after treatment $(85.0 \mathrm{~mm})$ proves a change of $4.48 \mathrm{~mm}$. Kusnoto et al. ${ }^{5}$ stated that each $\mathrm{mm}$ of lower incisive retraction will result in upper lip retraction of $0.4 \mathrm{~mm}$ and a lower lip retraction of $0.6 \mathrm{~mm}$. Kasai ${ }^{11}$ stating that the an upper incisive retraction of $4.3 \mathrm{~mm}$ causes the upper lip to move backward for $1.9 \mathrm{~mm}$.

Hagler et al. ${ }^{23}$ stated that the upper incisive retraction makes the upper lip move backward $2 \mathrm{~mm}$, while Drobocky et al. ${ }^{24}$ stated that four first premolar extraction causes the upper lip protrusion to be reduced $3.4 \mathrm{~mm}$. The comparison of the upper incisive retraction to the upper lip retraction according to Talaas et al. ${ }^{25}$ is 4.3:1.9 $\mathrm{mm}$. Kocadereli ${ }^{21}$ and Hagler et al. ${ }^{23}$ stated that premolar extraction followed by canine retraction and incisive retraction causes reduced lip convexity. The oral area has a big influence on facial soft tissue profile appearance. These changes are caused by orthodontic treatment causing positional change and lip shape change due to the fact that the lips are supported by the hard tissues that experience changes due to the orthodontic treatment. ${ }^{5}$ 
Soft tissue profile analysis on lower lip protrusion

This study results prove that the lower lip protrusion is reduced significantly at the end of the bimaxillary protrusion treatment with four first premolar extraction. This study result is similar to the results of Lew et al. ${ }^{6}$ on profile changes in dentoalveolar bimaxillary protrusion malocclusion treated by extracting four first premolars, i.e. there is a reduced lower lip protrusion of $3.6 \mathrm{~mm}$. Kusnoto et al. ${ }^{5}$ also stated that each $\mathrm{mm}$ of lower incisive retraction will produce upper lip retraction of $0.4 \mathrm{~mm}$ and lower retraction of $0.6 \mathrm{~mm}$. In this research ${ }^{5}$ the lower lip protrusion before the treatment is $86.9 \mathrm{~mm}$ and after the treatment it becomes 80.9 . Kasai ${ }^{11}$ also stated that each lower incisive retraction of $4.3 \mathrm{~mm}$ causes the lower lip move backward $3.1 \mathrm{~mm}$.

Hagler et al. ${ }^{23}$ stated that due to the lower incisive retraction, the lower lip moves backward $4 \mathrm{~mm}$. According to Drobocky et al. ${ }^{24}$ four first premolar extraction causes low lip reduction of $3.6 \mathrm{~mm}$. Lower lip incisive on lower lip retraction according Talaas et al. ${ }^{25}$ in his study is 2.4:3.1.

\section{CONCLUSION}

Treatment using Edgewise Standard device on dentoalveolar bimaxillary protrusion with four first premolar extraction shows an anteroposterior change in soft tissue profile that can be measured by using loi for soft tissue profile analysis which is an easy method. Therefore, it can be used as alternative in analyzing soft tissue profile. Further research is needed with a larger sample to get soft profile norm for certain race group.

\section{REFERENCES}

1. Erbay EF, Caniklioglu CM, Erbay SK. Soft tissue profile in Anatolian Turkish adults. Part I: Evaluation of horizontal lip position using different soft tissue analysis. Am J Orthod Dentofac Orthop 2002;121(1):57-64.

2. Holdaway RA. A Soft-tissue cephalometric analysis and its use in orthodontic treatment planning: Part I. Am J Orthod 1983;84:1-28.

3. Farrow AL, Zarrinia K, Azizi K. Bimaxillary protrusion in Black Americans-An esthetic evaluation and the treatment considerations.
Am J Orthod Dentofac Orthop 1993;104(3):24050.

4. Bills DA, Handelman CS, BeGole EA. Bimaxillary dentoalveolar protrusion: Traits and orthodontic correction. Angle Orthodontist 2004;75(3):333-9.

5. Kusnoto H. Penggunaan cephalometri radiografi di Bidang Ortodonti. Jakarta: 1977.

6. Lew K. Profile changes following orthodontic treatment of bimaxillary protrusion in adults with Begg Appliance. Eur J Orthod 1989;11: 357-81.

7. loi $\mathrm{H}$, Nakata S, Nakasima A, Counts AL. Anteroposterior lip positions of the most favored Japanese facial profiles. Am J Orthod Dentofac Orthop 2005;128:206-11.

8. Rakosi T, Jonas I, Graber TM. Color atlas of dental medicine: Orthodontic-diagnosis. New York: Thieme Medical Publishers Inc.; 1993.

9. Czarnecki ST, Nanda RS, Currir GF. Perceptions of a balanced facial profile. Am J Orthod Dentofac Orthop 1993;104:180-7.

10. Bergman RT. Cephalometric soft tissue facial analysis. Am J Orthod Dentofac Orthop 1999;116:373-89.

11. Kasai K. Soft tissue adaptability to hard tissues in facial profiles. Am J Orthod Dentofac Orthop 1998;113:674-84.

12. Moyers RE. Handbook of orthodontics. Chicago: Year Book Medical Publishers Inc.; 1998. p. 183-95.

13. Profit WR, Fields HW. Contemporary orthodontics. $3^{\text {rd }}$ ed. St. Louis: Mosby Year Book; 2000. p. 160-7.

14. Graber TM, Vanarsdall RL. Orthodontics: Current principles and techniques. $2^{\text {nd }}$ ed. St Louis: Mosby Year book Inc.; 1994. p. 45-76, 299-313.

15. Kurz C. The use of lingual appliances for correction of bimaxillary protrusion (four premolar extraction). Am J Orthod Dentofac Orthop 1997;112:357-63.

16. Brons R. Facial harmony standards for orthognatic surgery and orthodontic. Quintessence Publishing. London: 1998. p. 17 -39 .

17. Athanasiou AE. Orthodontics cephalometry. Missoury: Mosby-Wolfe; 1995. p. 48-92,241 $-86$.

18. Hwang HS, Kim WS, McNamara JA. A comparative 
study of two methods of quantifying the soft tissue profile. Angle Orthodontist 2000;70:2007.

19. Fitzgerald JP, Nanda RS, Currir GF. An evaluation of the nasolabial angle and the relative inclinations of the nose and upper lip. Am J Orthod Dentofac Orthop 1992;102:32834.

20. Viazis AD. Atlas of orthodontics: Principles and clinical applications. Philadelphia: W.B. Saunders Co.; 1993. p. 41-54.

21. Kocadereli I. Changes in soft tissue profile after orthodontic treatment with and without extraction. Am J Orthod Dentofac Orthop 2002;122:67-72.

22. James RD. A comparative study of facial profiles in extraction and non extraction treatment. Am J Orthod Dentofac Orthop 1998;114:26576.

23. Hagler BL, Lupini J, Johnston LE. Long-term comparison of extraction and nonextraction alternatives in matched samples of African American patients. Am J Orthod Dentofac Orthop 1998;114(4):393-403.

24. Drobocky OB, Smith RJ. Changes in facial profile during orthodontic treatment with extraction of four first premolars. Am J Orthod Dentofac Orthop 1989;95:220-30.

25. Talaas Mf, Talaas F, Baker RC. Soft-tissue changes resulting from retraction of maxillary incisors. Am J Orthod Dentofac Orthop 1987;91:385-94. 